\title{
Discourse, Cultural Capital and Power Relations in Julian Barnes's The Sense of an Ending
}

\author{
Eleftheria Karagianni \\ Independent researcher, Greece
}

The objective of this paper is to examine in which way the use of the oral and written discourse in Fulian Barnes's novel The Sense of an Ending (2011) reflects, on the one hand, a social hierarchy based on classificatory cultural, intellectual, and educational competencies and resources and, on the other, dominance strategies and power relations developed among the principal actors. It will be investigated how trivial discussions and letters exchanged between friends are deployed in order to sustain or eliminate control over the other(s) and indicate status positions. The proposed methodological framework of analysis is founded on Bourdieu's approach to cultural capital, according to which cultural preferences are markers of social stratification, while highbrow aesthetic judgment is both a means to, and a stake in, upward social mobility. Foucault's theory of a "decentralised" and ubiquitous power, dispersed at all levels and defined as an action directed to other people's actions, will also be applied.

Keywords

Julian Barnes; The Sense of an Ending; discourse; cultural capital; power

\section{Introduction}

Julian Barnes's The Sense of an Ending was published in 2011 and gained immediate recognition not only by readers and critics, but also by researchers in the academic community. The principal figure of the novel, Tony, a senior citizen, receives a letter one day informing him that he has inherited the amount of $\iota_{5} \mathrm{Oo}$ and the diary of a long-deceased friend. The name of the testator, Sarah Ford, a woman whom Tony had only met once in his life, the mother of an old girlfriend of his during the first years of college, will trigger a painful confrontation between him and his up to then selectively recalled past. The Sense of an Ending is separated into two distinct parts. In the first, 


\section{ELEFTHERIA KARAGIANNI}

Tony introduces us to the carefree and unworried youth he shared with his three rather unconventional, passionate and sophisticated friends. This part of the book consists of impressions and emotions that Tony experienced in his school and later in his student, personal and social life. In the second part, we meet Tony again many decades later, as a divorced, compromised elderly man in his sixties, with a rather flat, dull and lonely life. The only remarkable thing happening to him seems to be the arrival of this strange and unexpected letter from the law firm, which will activate, exactly as the crumbs of a madeleine did for Proust, the process of recalling information stored in his memory. Tony, despite being sunk for many decades into the oblivion of a "peaceable" life, will be forced to reconstruct the time of his youth, in order to be able to find convincing answers to the causes of his old school friend's death. During this agonising process he will have to recount in detail certain incidents, invoke repressed emotions, clear up blurry scenes and finally explain the motives of certain acts which resulted in consecutive tragedies. Tony's subjective perception of facts, biased interpretation of signs, and vicious feelings will be gradually revealed and re-examined as a sine qua non condition of arriving at the truth.

As a result of this unexpected inheritance, Tony will be obliged to reestablish contact with his college girlfriend Veronica Ford in order to claim what has been bequeathed to him: Adrian Finn's diary. Veronica, for her part, by invoking a superior moral code of privacy and respect for intimacy regarding personal records, keeps the diary in her possession and refuses to deliver or show it to Tony, disregarding her mother's testament and last will about Adrian's diary passing into Tony's hands. Relenting though, due to his persistence and determination to face the past, she provides photocopies of two original and crucial documents: Tony's aggressive letter sent to Adrian and her, many years ago, and a short but significant extract of Adrian's diary in which the latter tries to philosophically and mathematically explain the reasons that led him to kill himself. It will be proved that those two documents are interrelated, and that the content of Tony's letter - in which he denigrates Veronica, and urges Adrian to contact Sarah Ford, Veronica's mother, so that she may corroborate his story - will initiate a relationship between Sarah and Adrian, which will end with the birth of their handicapped child, and with Adrian's suicide.

Studies on Barnes's The Sense of an Ending have been mostly focused on the themes of memory and time. In this "confessional novel" (Piciucco 43) 
of "agitated reminiscence" (Callus 55) all events are recalled by Tony, who is not only a narrator, but also "a creator of fiction inside a world of fiction" (Rossi 176). Narrator as protagonist and protagonist as narrator will be placed face to face in "dialogic opposition" (Piciucco 44), embodying "two distinct roles and identities in relation with the flow of time" (43). Tony's deceitful and distorted memory (Piqueras 9o) will render him an unreliable witness of his own past. In the Sense of an Ending, "any attempt at representing time, reality or order in the mind or in the universe, history or one's own life story, is eventually depicted by Barnes as unavoidably incomplete and unsatisfactory" (Vecsernyés 40).

The present paper intends to contribute to academic research by shedding light on the motives of an act around which revolves the central theme of the book: the letter that Tony sent to Adrian Finn and Veronica Ford as a reply to the announcement of their relationship and, as will be analysed in the next section, the impact of this initiative in all of the involved persons' lives. It will be explored to what extent oral discourse manifests aspects of cultural capital and classification, and what the aftereffects of Tony's recognition of his friend Adrian's and his girlfriend Veronica's cultural and educational supremacy are. It will also be revealed that Tony's improper use of the written, the lack of convincing arguments and evidence to support his claim about Veronica's character and real intentions is a reaction to being symbolically dominated and considered inferior by Veronica herself, her family, and also by his friend, Adrian.

As Tony appears completely incapable of responding adequately to the supremacy of a cultural and educational elite, he takes action by distorting facts and presenting unverified and unprovable assumptions as real events. The letter he finally sends to the new couple constitutes a "palinode" of his first writing effort: a card that will never be sent, and in which Tony initially expresses formally and decently his approval of Adrian and Veronica's affair. The word "palinode", a " $\pi \alpha \lambda \iota v \omega \delta i \alpha "$ (palinodia), is an ancient Greek word which refers to a new ode which retracts the content of a previous one and is used metaphorically in the sense of a reversal of opinion and of rescinding views that have already been expressed (Demos 235, 246). Tony's second attempt to reply to Adrian and Veronica is concluded with a palinode letter of ambivalent insinuations and unverifiable allegations. Through his wording, he will confine and trap all the persons involved in a resemblance of truth, which generates successive tragedies: Adrian's suicide, his illegitimate and 
disabled child with Veronica's mother, and Veronica's lifetime of suffering. After that, Tony's memories will be replaced for a long time by blurry and subjective impressions.

\section{Discourse and cultural capital}

In the first part of the book, the principal figure, Tony, refers mainly to two persons: Adrian and Veronica. Adrian Finn is the new member in the group of three close friends and classmates, a well-behaved, gifted, and very promising student. His perspicacity, extraordinary school achievements, and profound knowledge in various subjects, along with his eloquence and rare talent in developing philosophical and rhetorical arguments, evoke admiration and assure him a grant at Cambridge. Later on, during the first two years of his college life in Bristol, Tony gets involved with an equally bright, dynamic and cultured middle-class girl, Veronica Ford. She is described as quite dominant and judgmental about Tony's aesthetics, music and reading tastes, and as someone who has an air of superiority, exercising total control over him, even during their intimate moments. While visiting Veronica's family house for a weekend, he will make acquaintance with her brother, a prominent Cambridge student, her scornful and rather gross father to whom Veronica seems to be very special, and her very mysterious mother who does not seem to value her daughter highly. After a while, Tony decides to leave Veronica in a very humiliating way, probably as retaliation for being treated as substandard by her and her family.

Tony's feelings and reactions, but also the words he chooses to describe Adrian and Veronica, disclose his sense of their displaying a high level of "cultural capital". By cultural capital, Bourdieu refers to "knowledge, skills, and other cultural acquisitions, as exemplified by educational or technical qualifications" (Bourdieu, Language and Symbolic Power 14). Cultural capital may be inherited through family, academically acquired, or "built" with the aid of financial resources. It is also classified in three distinct categories: A) The embodied, manifested in the form of habits, beliefs, style, taste and mannerisms, presupposing inculcation and assimilation; B) The institutionalised, connected to academic qualifications, extraordinary skills, awards, distinctions and honours; C) The objectified, linked to property and assets (Bourdieu, "The Forms of Capital" 243-248). Cultural capital on one hand facilitates social mobility, especially by means of school and academic achievements, and 
on the other sets barriers as it is associated with the practices applied and imposed by the dominant culture. It constitutes a factor of hierarchisation and distinction, connected to a cultural nobility, or an aristocracy of culture (Bourdieu Distinction, 13; 23), attributed with qualities such as popularity, eloquence, prestige, and reputation.

In Barnes's novel, Tony, on many occasions, when he recollects certain situations and reproduces dialogues verbatim, stresses Adrian's acquired and superior institutionalised cultural capital which provides him with acceptance, recognition, future success and access to the upper social class. By admitting Adrian's exceptional competences and talents, Tony constructs a space of social positions and roles in which he places himself at a lower level in prestige grading. This thesis is confirmed by Tony's following statements:

At morning prayers he could be heard joining in the responses while Alex and I merely mimed the words, and Colin preferred the satirical ploy of the pseudo-zealot's enthusiastic bellow. The three of us considered school sports a crypto-fascist plan for representing our sex-drive; Adrian joined the fencing club and did the high jump. We were belligerently tone-deaf; he came to school with his clarinet (Barnes 7).

[...] we envied Adrian... (Barnes 9).

[...] we wanted his attention, his approval; (Barnes 19).

Old Joe Hunt looked at his watch and smiled. Finn, I retire in five years. And I shall be happy to give you a reference if you care to take over (Barnes 12).

Adrian to nobody's surprise won a scholarship to Cambridge (Barnes 19).

Adrian was much more clever than me - he used his logic where I used common sense... (Barnes 104).

Tony provides us also with extended information on his then girlfriend Veronica, putting emphasis on her social provenance and heightened sense of taste and aesthetics as synonymous with superior social ability:

My girlfriend was called Veronica Mary Elizabeth Ford. [...] She was 


\section{ELEFTHERIA KARAGIANNI}

reading Spanish, she liked poetry, and her father was a civil servant (Barnes 20).

[She] had better musical taste (Barnes 20).

Along with all the indications of Adrian's recognised academic competence, and Veronica's high level cultural capital and highbrow taste and activities, Tony's testimonies also manifest his own limited potential, "average, that's what I'd been ever since I left school" (Barnes 10o), and restricted access to what Bourdieu calls "legitimate culture", meaning the prevailing culture of the dominant class (Bourdieu, Language and Symbolic Power 16). The legitimate culture is expressed by the "legitimate taste", that is the social elite's established perception of refined goods, which produces and reproduces social inequalities. For Bourdieu, "taste classifies, and it classifies the classifier... [it] is the basis of all that one has, people and things and all that one is for others, whereby one classifies oneself and is classified by others" (Bourdieu Distinction $\left.5^{6}\right)$. Distinguished tastefulness is nothing but "a practical affirmation of an inevitable difference" (Bourdieu Distinction 56). In other words, aesthetic sense becomes a "distinctive expression of a privileged position in social space" (Bourdieu, Distinction 56). In Bourdieu's theory, cultural practices, cultural judgement and consumption of cultural goods, constitute indicators of social origins. It seems that Tony realises that prima facie innocent and trivial discussions about literature, music, dance, books, or argumentation over school subjects, such as poetry and history, convey marks of classification and hierarchy. Veronica's legitimate and selective taste leads Tony to perceive their affair as unequal and antagonistic, as a relationship between inferiorsuperior social beings, a tension between acceptance-rejection, lowbrow and highbrow culture.

My bookshelves were more successful with Veronica than my record collection (Barnes 23).

Veronica paid me the complement of assuming I'd read them all, and didn't suspect that the most worn titles had been bought second hand. Her own shelves held a lot of poetry, in volume and pamphlet form (Barnes 24).

I didn't for a moment doubt that she had read them all, or that they were the 
right books to own. Further, they seemed to be an organic continuation of her mind and personality, whereas mine struck me as functionally separate, straining to describe a character I hoped to grow into. This disparity threw me into a slight panic... (Barnes 24).

She looked through my record collection with an occasional flickering smile and a more frequent frown. The fact that I'd hidden both the 1812 Overture and the soundtrack to Un Homme et Une Femme didn't spare me (Barnes 21).

As Bourdieu demonstrates in Distinction, tastes or manifested preferences are mere affirmation of a difference, and are asserted negatively by rejecting other tastes. Taste for Bourdieu is defined by distaste, and intolerance towards other people's preferences (Bourdieu, Distinction ${ }_{5} 6$ ). Intolerance towards low-brow aesthetics may be severe, while "aversion to different life-styles is perhaps one of the strongest barriers between the classes" (Bourdieu, Distinction 56). The way somebody chooses and uses cultural and symbolic goods, especially those which are considered to be "of excellence", indicates not only class stratification, but also schemes and tactics of class and cultural prevalence.

Veronica's predilection for legitimate cultural practices and preferences are related to what Bourdieu calls habitus. Habitus is a system of "dispositions" (Bourdieu, Distinction 6) that structures the way we perceive the world, and subconsciously determines our attitude, behaviour, mindset and choices regarding cultural goods and activities. It betrays, no matter how hard a person tries to disclose it, social and class origins, and results from instilled habits, tastes, practices and customs ingrained during upbringing. Habitus is also a classificatory parameter. More precisely,

the habitus is both the generative principle of objectively classifiable judgements and the system of classification (principium divisionis) of these practices. It is in the relationship between the two capacities which define the habitus, the capacity to produce classifiable practices and works, and the capacity to differentiate and appreciate these practices and products (taste), that the represented social world, i.e., the space of life-styles, is constituted (Bourdieu, Distinction 170).

Tony is literally confronted with Veronica's cultural capital and habitus not 


\section{ELEFTHERIA KARAGIANNI}

only during their meetings, but also during the weekend with Veronica's family, where he feels betrayed by her, strongly underestimated and treated as inadequate:

I couldn't tell if he [Veronica's father] was being all matily male, or treating me as lower-class scum (Barnes 27).

He [Veronica's brother] behaved towards me as if I were an object of mild curiosity, and by no means the first to be exhibited for his appreciation (Barnes 27).

Over supper that Friday there was some questioning of my social and intellectual credentials; I felt as if I were before a court of inquiry (Barnes 28).

[...] she [Veronica] mentioned colleges and dons and tea shops in a way that made me feel left out (Barnes 31 ).

"What's Jack reading?" I asked, trying to make up ground.

"Moral sciences" she replied. "Like Adrian."

I know what Adrian's bloody reading, thank you very much, I wanted to say. Instead I sulked for a while and talked to Colin about films (Barnes 31).

But whenever I looked back on that unhappy weekend, I realized that it hadn't been just a matter of a rather nad've young man finding himself ill at ease among a posher and more socially skilled family. That was going on too, of course. But I could sense a complicity between Veronica and her heavy-footed, heavy-handed father, who treated me as substandard (Barnes 43).

Tony's sense of being subconsciously and symbolically low-ranked was intensified by the possessions of Veronica's family which proved their uppermiddle-class status such as their polished furniture, or their Humber Super Snipe, driven at that time by wealthy people of a certain financial situation such as executives, government officials, etc. Things were also aggravated by her father's condescending jokes and rather exaggerated enthusiasm about the historical sites and prestigious haunts of their region, confirming and maybe reminding Tony of the Fords' family social position. 
At the station, Veronica introduced me to her father, who opened the boot of his car, took the suitcase from my hand, and laughed. 'Looks like you're planning to movein, young man' (Barnes 26).

When I came downstairs to say goodbye, Mr Ford seized my suitcase and said to his wife, 'I trust you've counted the spoons darling?' (Barnes 30).

'St Michel's brick and flint, much improved by Victorian restorers'... 'Our very own café Royal - voilà!'... 'Note the distinguished off-licence with period half-timbering on your right' (Barnes 26).

It has been revealed so far that thoughts and feelings described by Tony, along with the reported dialogues and repetition of the actual words as they have been spoken imply gradations of cultural capital, classifications and symbolic hierarchies. Tony's lack of academic success and highbrow cultural preferences, his deficiency in adoption and promotion of what is called "legitimate" taste are reflected in the discourse, intensifying the contrast between Adrian's, Veronica's, her family's and his own status, a condition that finally generates among them cultural distinction and social division.

\section{Discourse and power}

In "The Discourse in Language", Foucault stresses the importance of discourse, as human and power relations are constructed through and in it. Not only does it allow a system of power to be expressed, but also contributes to the constitution of this system. More precisely, in Foucauldian theory, discourse practices produce information, knowledge and desires related to dominance, constructing in parallel that particular system of dominance (Lyrintzis 6-7). Nonetheless, it cannot operate autonomously. In every society, discourse is "controlled, selected, organized and distributed according to a certain number of procedures, whose role is to avert its powers" (Foucault, "The Discourse in Language" 216).

In the first part of the book, Tony's description of facts reveals his sense of being, in Foucauldian terms, a subject "conducted" or "governed" by Adrian's and Veronica's power. He names his feelings in the second part of the book, when he tries to identify the nature of his relationship with Veronica: 


\section{ELEFTHERIA KARAGIANNI}

I was someone who had gone out with the daughter of Mrs Sarah Ford (deceased) for a period of about a year, who had been patronized by her husband, loftily scrutinized by her son, and manipulated by her daughter (Barnes 64).

Her [Veronica's] attitude towards me, now that I looked at it, had been consistent - not just in recent months, but over however many years. She had found me wanting, had preferred Adrian, and always considered these judgements correct (Barnes 130).

The version of my relationship with Veronica, the one that I'd carried down the years, was the one I'd needed at the time. The young heart betrayed, the young body toyed with, the young social being condescended to (Barnes 122).

Power for Foucault is not necessarily enforcement, but a means to transform a person into a subject, and operates indirectly, constantly, without violence or loss of freedom. It is mostly "a way in which certain actions modify others" (Foucault, "The Subject and Power" 788), and an "action upon an action" (Foucault, "The Subject and Power" 789). Power relationships are embedded in society, omnipresent in all human interactions (Foucault, "The Subject and Power" 778; 791), and are understood as "a multiplicity of force relations immanent in the sphere in which they operate and constitute their own organization" (Foucault, The History of Sexuality, 9o).

In Foucault's approach, power does not abolish the freedom of the subject. On the contrary, the subject maintains the right of choice among various ways of acting. Neither does it necessarily require confrontation, servitude or submission, but rather an "interplay", an interaction among the subjects. Foucault calls that interplay "agonism" which means combat in Ancient Greek. "Agonism" is perceived as the "reciprocal incitation and struggle", a "permanent provocation" among the acting subjects (Foucault, "The Subject and Power" 790). The French philosopher defines the terms "conduct" and "government": "To conduct" someone means more than to behave in a certain manner. It signifies that somebody acts upon another person's act by leading and guiding him or her, aiming at a certain outcome. Subsequently, to conduct is not to confront, but to orient somebody towards "government", in the sense of directing someone's acts: 
Basically power is less a confrontation between two adversaries or the linking of one to the other than a question of government. This word must be allowed the very broad meaning which it had in the sixteenth century. "Government" did not refer only to political structures or to the management of states; rather, it designated the way in which the conduct of individuals or of groups might be directed: the government of children, of souls, of communities, of families, of the sick. It did not only cover the legitimately constituted forms of political or economic subjection but also modes of action, more or less considered or calculated, which were destined to act upon the possibilities of action of other people. To govern, in this sense, is to structure the possible field of action of others (Foucault, "The Subject and Power" 789-79o).

As I have argued in the previous section, insubstantial and ordinary dialogues in Barnes's book are transformed into a field of symbolic hierarchy, competition and dominance. Adrian, for example, appears to confirm his cultural mastery and impose through it his distinct, prevailing position and superiority towards the others when he states:

'I hate the way the English have of not being serious about being serious. I really hate it' (Barnes 33).

And then Veronica on her side seems overwhelmed by the desire to "conduct" Tony, and act upon his acts:

'I don't dance,' she said, part anthropologist, part layer-down of rules for any relationship we might have, were we to go out together (Barnes 21).

'Well, now you're at university we must get you to think for yourself, mustn't we?' (Barnes 25).

She was looking at me with one eyebrow raised above the frame of her glasses [...]. She was just trying to improve me - and who was I to object to that? (Barnes 25).

He [Veronica's brother] was the appointed judge when she [Veronica] asked publicly of me - and the question gets more condescending with each repetition - 'He'll do, won't he?' (Barnes 43). 


\section{ELEFTHERIA KARAGIANNI}

I was aware that Veronica had taken off her seat belt and was opening her door. As I started to do the same, she said, 'Stay.' I might have been a dog (Barnes 127).

Veronica seems to also dominate and regulate Tony's sexuality. During their relationship she is the one who sets the rules, directs and channels their sexual interplay and behaviour. According to Foucault (History of Sexuality 1978), power over sex is confirmed through imposition, interdiction, secrecy and limits. Historically, since the second part of the $19^{\text {th }}$ century, the bourgeoisie tried to "provide itself with a body and a sexuality" in order "to ensure the strength, endurance, and secular proliferation of that body through the organization of a deployment of sexuality" affirming thus its differentiation in relation to the other social classes, and at the same time its hegemony over them (Foucault History of Sexuality, 125-126). Foucault introduces the concept of "bourgeois and class sexualities", and the idea of an originally and historically bourgeois eroticism, "that in its successive shifts and transpositions, induces specific class effects" (Foucault History of Sexuality, 127). Veronica's prudery and self-restraint, compatible with her class ethos and upbringing, set the sexual rules of their relationship and manifest power and control exercised by her over Tony:

Had we been in a novel, there might have been some sneaking between the floors for a hot cuddle after the paterfamilias had locked up for the night. But we weren't; Veronica didn't even kiss me goodnight the first evening, or make some excuse about towels, and seeing I had everything. (Barnes 28)

Her command over the condition and the evolution of their love affair is reflected even when she decides to oppose the rules she had set herself from the beginning: "After we broke up, she slept with me" (Barnes 36 ).

Things though are gradually reversed in Tony's favour culminating with the inappropriate letter sent to Veronica and to Adrian. By exposing Veronica's alleged "damaged" and "active" sexuality and by making indecent comments about Veronica's supposed sexual "skills" (Barnes The Sense of an Ending, 9597), Tony seeks to master, control and direct the new couple's erotic life and deprive it of dignity. In his letter, Tony seems to also recognise and describe the effects of Veronica's symbolic power over him during their relationship "...because boy is that girl a control freak..." (Barnes 96). 
For Bourdieu, symbolic power is "a power that can be exercised only if it is recognized, that is misrecognized as arbitrary. That means that symbolic power does not reside in 'symbolic systems' in the form of an 'illocutionary force' but that it is defined in and through a given relation between those who exercise power and those who submit to it" (Bourdieu, Language and Symbolic Power 170). This recognition will lead Tony to employ the written discourse as a "recalibration" of the "dynamics of his relationships", as he says referring to his attempt to maintain contact with his friends, after they have left school and been separated.

We swore to meet every time the three of us at university came home for vacation; yet it didn't always work out. And writing to one another seemed to have recalibrated the dynamics of our relationship (Barnes 19).

Tony uses the same channel of communication in order to adjust and assess his relationship with Adrian, in a very different context this time and with a different objective, treating his friend not as a close friend, a highly appreciated person and a member of the same clique, but as a rival. As Foucault claims in his study Punitive Society (2015), distrust and competition prevail among human beings, and the only way for one person to terminate this condition is to strengthen his power and exercise absolute authority over the others. For the French philosopher, a subject achieves that through the appropriation a) of an object of pleasure and b) of a tool to acquire that object. In this way, the subject gains something very important: a condition in which no one seeks any more to substitute him, and therefore s/he commands respect. Tony's letter derives from competition and distrust towards Adrian and Veronica, and constitutes a tool to claim Veronica as an object of pleasure not by desire, but by pure display of power. It is Tony's way to protest and express his aversion to being treated as a substitute and transformed into a Foucauldian subject. It is his reaction to having been not only directed, guided and governed, but also underrated, looked down on, treated with contempt (Barnes 69, 130), and excluded by the ambassadors of the embodied and institutionalised state of cultural capital: Veronica and Adrian.

I also liked the hypocrisy of a letter whose point was not just to tell me something I might not have found anyway (or not for quite a while), but to let me know how she, Veronica, had traded up: to my cleverest friend, and what's more, a Cambridge chap like Brother Jack. Also to warn me 


\section{ELEFTHERIA KARAGIANNI}

that she should be hanging around if I planned on seeing Adrian - which had the desired effect of making me plan not to see Adrian (Barnes 41).

His writing is an act upon Adrian's and Veronica's acts, and an implementation of concrete strategies, allowing him to exercise, in his turn, power over them. By using Foucault's concept one more time, I claim that Tony's writing is actually a planned and directed strategy executed in three steps as defined by Foucault in "The Subject and Power" (793):

It is a question, therefore, of the means destined to obtain victory. These three meanings come together in situations of confrontation, war or games, where the objective is to act upon an adversary in such a manner as to render the struggle impossible for him. So strategy is defined by the choice of winning solutions (Foucault, "The Subject and Power" 793).

First, Tony chooses the means to attain his goal. Second, he designates the way in which in this game of power "he acts with regard to what he thinks should be the action of the others and what he considers the others think to be his own; it is the way in which one seeks to have the advantage over others" (Foucault, "The Subject and Power" 793). Third, in this confrontation, he tries to defeat Adrian and Veronica by depriving them of their means of "combat" - as, for example, their academic or social superiority, their educational credentials and disposition of cultural capital, the power they exercise over others through their highly valued taste, skills and competences, and the respect they inspire (Adrian) or impose (Veronica). Under this perspective, Tony's intentions are understood within the framework of intensification of his power, and the parallel limitation of that of Adrian's and Veronica's. His goal is to confront his adversaries by rendering them his own subjects. As Foucault claims,

between a relationship of power and a strategy of struggle there is a reciprocal appeal, a perpetual linking and a perpetual reversal. At every moment the relationship of power may become a confrontation between two adversaries. Equally, the relationship between adversaries in society may, at every moment, give place to the putting into operation of mechanisms of power (Foucault, "The Subject and Power" 794).

In The Sense of an Ending, Tony's letter is the catalyst for change in the main figures' lives, including his. From the moment he turns from recipient to 
expeditor, power relationships are reversed, rules are changed and a borderline, pyrrhic victory is obtained with collateral damages, pain, and losses. His pyrrhic victory appears to have resulted only in a short-term and superficial satisfaction, in the sense that he enjoyed the instant pleasure of taking power over Adrian and Veronica by affecting their lives, when in reality he only inadvertently caused pain and suffering for everybody, including him. Tony, the only survivor of an undeclared war, after discovering the truth and the consequences of his victory with practically no gains for him and total destruction for the others, confesses to himself:

I survived. 'He survived to tell the tale' - that's what people say, don't they? History isn't the lies of the victors, as I once glibly assured Old Joe Hunt? I know that now. It's more the memories of the survivors, most of whom are neither victorious nor defeated. (Barnes The Sense of an Ending, 56)

\section{Conclusion}

In the present study of Barnes's novel The Sense of an Ending, I tried to highlight the implicit evidence of cultural and class stratification, along with a progressive control, expressed through oral and written discourse, which conforms to the theoretical works of Pierre Bourdieu and Michel Foucault. It was revealed that the narrator's representation of events suggests his latent sense of being deficient regarding intellectual and social skills, academic achievements, cultural practices, and taste. It was also proved that his writing is an act directed towards the symbolic power exercised over him, and at the same time an exhibition of his power over the others. The central figures of the novel are subjects of a dynamic, productive power (Lewandowski 1995) based not on violence, suppression, and deprivation of freedom, but on their "alternating" constant efforts for control exercise, which ends in defining their acts in a fatal and tragic way. Discourse in Barnes's novel indicates superior and inferior status, and distinction resulting either from school and academic performance (Adrian and Jack), or from legitimate culture and taste adopted by the British middle-class elite of that time (Veronica and her family). The discourse states that cultural capital and power are used as a strategic means, which not only conducts and regulates Tony's, Veronica's, and Adrian's social and sexual relations, but also classifies them in social categories and hierarchies, and determines their dominant-dominated positions. 


\section{Works Cited}

Alaszewski, Andy. "Diaries as a source of suffering narratives: A critical commentary." Health, Risk \& Society 8(2006) pp. 43-58.

Barnes, Julian. The Sense of an Ending. London: Penguin Vintage, 2017.

Bourdieu, Pierre. "The Forms of Capital." In Handbook of Theory and Research for the Sociology of Education. Ed. J., Richardson. Westpoint, CT:Greenwood, 1986. $241-25^{8}$.

---. Language and Symbolic Power. Oxford: Polity Press, 1991.

---. Distinction: A Social Critique of the fudgment of Taste. Cambridge, Massachusetts: Harvard University Press, 1996.

Callus, Ivan. "There is Great Unrest': Some Reflections on Emotion and Memory in Julian Barnes Nothing to Be Frightened Of and The Sense of an Ending." Prague fournal of English Studies 1(2012), pp. 55-72.

Demos, Marian. "Stesichorus' Palinode in the 'Phaedrus'." The Classical World 9o/4 (1997), pp. 235-249.

Foucault, Michel. "The Discourse on Language." In M. Foucault, The Archeology of Knowledge and The Discourse on Language. New York: Pantheon Books, 1972. 216-237.

--. 1978. The History of Sexuality. Volume 1, An Introduction. New York: Pantheon Books.

---. "The Subject and Power." Critical Inquiry 8(4) 777-795, 1982.

---. The Punitive Society: Lectures at the Collčge de France 1972-1973. Ed. Arnold I. Davidson. London, New York: Palgrave Macmillan, 2015.

Lewandowski, Joseph D. "Rethinking Power and Subjectivity after Foucault." Symplokç 3/2 (1995), pp. 221-43.

$\Lambda$

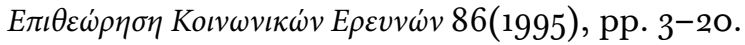

[Translation of the Greek article: Lyrintzis, Christos. "On Power: Foucault and the Analysis of a Controversial Notion." The Greek Review of Social Research 86(1995), pp. 3-20. DOI:https://doi.org/10.12681/grsr.665.]

Oró Piqueras, Maricel. "Memory Revisited in Julian Barnes' The Sense of an Ending." Coolabah 13 (2016), pp. 87-95.

Piciucco, Pier, Paolo. "The Ageing Confessor and the Young Villain: Shadowy Encounters of a Mirrored Self in Julian Barnes' The Sense of an Ending." In Imagining Ageing: Representations of Age and Ageing in Anglophone Literatures. Ed. Carmen Concilio. Bielefeld: Transcript Verlag, 2018. 41-6o.

https://www.degruyter.com/transcript/view/book/9783839444269/10.14361 /9783839444269-005.xml Accessed on 19 October 2020. 
Rossi, Alberto. "Memory, Truth, and Différance in Julian Barnes' The Sense of an Ending." Iperstoria 8(2016), pp. 171-185.

Vecsernyés Dóra. "With His Watch on the Inside of the Wrist: Time in Julian Barnes' The Sense of an Ending." In Stunned into Uncertainty: Essays on Fulian Barnes' Fiction. Ed. Tory Eszter and Janina Vesztergom. Budapest: Department of English Studies, 2014. 29-40. https://www.academia. edu/35100823/With_His_Watch_on_the_Inside_of_the_Wrist_Time_ in_Julian_Barnes_s_The_Sense_of_an_Ending Accessed on 4 November 2020.

ELEFTHERIA KARAGIANNI is an independent researcher and holds a Ph.D. in Political Science from the National and Kapodistrian University of Athens, Greece. She has studied French Literature, Sociology, and Political Science in Greece and in France. Her current research and publications focus on social and political theories and representations in European and American literature. She is currently conducting research on the social and political representations of Nazism and totalitarianism in literature.

\section{e.karag@gmail.com}

